\title{
Quality of Life as an Independent Predictor for Cardiac Events and Death in Patients With Heart Failure
}

\author{
Naoko Kato, PhD; Koichiro Kinugawa, MD, PhD; Satomi Seki, BSc; Taro Shiga, MD, PhD; \\ Masaru Hatano, MD; Atsushi Yao, MD, PhD; Yasunobu Hirata, MD, PhD; \\ Keiko Kazuma, PhD; Ryozo Nagai, MD, PhD
}

\begin{abstract}
Background: Little is known about health-related quality of life (QOL) in Japanese patients with heart failure. The purpose of this study was to identify factors related to QOL using a disease-specific QOL instrument, and to clarify whether QOL independently predicts clinical outcomes among Japanese patients with heart failure.
\end{abstract}

\begin{abstract}
Methods and Results: A total of 114 outpatients with heart failure were enrolled (mean age $64.7 \pm 15.8$ years; 73.7\% males). The Minnesota Living with Heart Failure Questionnaire (MLHFQ) to assess patient's QOL was used. At baseline, depressive symptoms and chronic kidney disease were significantly associated with worse QOL in multiple regression analysis. During a 2-year follow up, patients with a MLHFQ score $\geq 26$, indicating worse $Q O L$, had a higher incidence of the combined endpoint of cardiac death or hospitalization for heart failure, and a higher all-cause mortality than those with a score $<26$ (25.3\% vs. $7.5 \%, P=0.011 ; 18.5 \%$ vs. $6.4 \%, P=0.018$; respectively). Multivariate Cox proportional hazard models demonstrated that a higher MLHFQ score was significantly associated with increased risks of cardiac events (hazard ratio, 1.02, 95\% confidential interval, 1.001-1.05, P=0.038) and of all-cause death (hazard ratio, 1.04, 95\% confidential interval, 1.02-1.07, P=0.001).
\end{abstract}

Conclusions: Depressive symptoms and chronic kidney disease are major determinants of impaired QOL, and the MLHFQ score is an independent predictor of both cardiac events and death among Japanese patients with heart failure. (Circ J 2011; 75: 1661-1669)

Key Words: Heart failure; Hospitalization; Mortality; Quality of life

$\mathbf{H}$ eart failure is a universally prevalent, money-consuming, and long-standing condition associated with heavy symptom burden, high mortality, and frequent hospital admission., ${ }^{1,2}$ Since recent advances in treatment have prolonged life expectancy, greater attention has now been paid to improving health-related quality of life (QOL) in patients with heart failure. Heart failure patients experience high levels of physical, functional and emotional distress. Their QOL is not able to be normalized even with optimal treatment, ${ }^{3-5}$ and are usually worse than other common chronic diseases (ie, hypertension, angina, chronic lung disease, or arthritis). ${ }^{5}$

Comprehension of factors associated with patient's QOL could help health professionals to outline strategies during management of heart failure, and not only focus on objective goals, but also on the patient's perception. Prior studies have shown limited associations between heart failure severity and health status measures including symptoms, functional status and QOL, ${ }^{6,7}$ suggesting that other factors than disease severity might be important in determining the health status of patients with heart failure. Depressive symptoms could be one of such factors, ${ }^{8-10}$ but it still needs to be elucidated. Moreover, most of the previous studies investigating QOL of heart failure patients were performed mainly in the USA and Europe; there has been only a few studies in Japan. ${ }^{3,4}$ The Japanese studies investigating QOL of heart failure patients used the generic QOL instruments such as Short-Form 36, and did not focus on identifying factors associated with QOL., In order to assess more precisely the symptoms and health impacts of heart failure, heart failure-specific QOL instruments have been widely used. ${ }^{11}$

According to the literature, a lot of markers seem to have prognostic values and might be used for risk stratification in heart failure. Recently, a systematic review has revealed that

Received January 5, 2011; revised manuscript received February 14, 2011; accepted March 9, 2011; released online April 29, 2011 Time for primary review: 13 days

Department of Cardiovascular Medicine (N.K., K. Kinugawa, T.S., M.H., A.Y., Y.H., R.N.), Department of Adult Nursing (S.S., K. Kazuma), Graduate School of Medicine, The University of Tokyo, Tokyo, Japan

This study was supported in part by a Grant-in-Aid for the JSPS Postdoctoral Research Fellow from the Japan Society for the Promotion of Science (no. 224943) to N.K..

Mailing address: Naoko Kato, PhD, Department of Cardiovascular Medicine, The University of Tokyo Hospital, 7-3-1 Hongo, Bunkyo-ku, Tokyo 113-8655, Japan. E-mail: naokat-tky@umin.ac.jp

ISSN-1346-9843 doi:10.1253/circj.CJ-10-1308

All rights are reserved to the Japanese Circulation Society. For permissions, please e-mail: cj@j-circ.or.jp 
health status assessed by the QOL instruments is a strong predictor of the combined endpoint of death and hospitalization, but is not predictive of all-cause mortality. ${ }^{12}$ Moreover, previous results of the predictability of the QOL score in clinical outcomes after adjustment for disease severity and other prognostic factors have been inconsistent. ${ }^{13-18}$ Thus, it remains unclear whether the QOL score provides useful prognostic information in addition to objective indicators.

The purpose of this study was therefore: (1) to identify factors related to QOL using the heart failure-specific QOL instrument; (2) to clarify whether the QOL score predicts the combined endpoint of cardiac death or hospitalization for heart failure as well as all-cause death and (3) to examine whether the QOL score can be an independent prognostic factor in Japanese patients with heart failure.

\section{Methods}

\section{Study Design and Study Patients}

This study was a prospective cohort study of outpatients with heart failure. The institutional review board of the University of Tokyo approved this study. All participants provided informed consent. The detail of this study design was described previously. ${ }^{19-21}$ In brief, all consecutive outpatients with heart failure who were making scheduled visits to the cardiovascular outpatient clinic of the University Hospital in Tokyo between July 2006 and November 2006 were enrolled. The attending physician determined whether each patient met our criteria based on medical records and the patient's symptoms. Patients were included when they were diagnosed with heart failure in accordance with Framingham heart failure criteria, ${ }^{22}$ were at least 20 years of age, and did not undergo hemodialysis. ${ }^{23}$ Exclusion criteria were physical inability to complete the questionnaire and inability or unwillingness to give informed consent. Patients were followed up for a median period of 2.1 years, and they received usual care from their primary care physicians and/or their cardiologists.

\section{Endpoints}

The primary endpoint was the combined endpoint of cardiac death or hospitalization for heart failure. Hospitalization for heart failure was defined as an admission primarily diagnosed with heart failure. We considered all-cause death as secondary endpoints. The information on endpoints was collected from medical records. We also mailed a follow-up letter to all patients or their family approximately 2 years after the initial assessment to enquire about the patients' clinical outcomes. If the requested information was not received within 4-6 weeks after the mailing, we asked the attending physicians about the patient's clinical outcomes.

\section{Heart Failure-Specific QOL Instrument}

We used the Minnesota Living with Heart Failure Questionnaire (MLHFQ) ${ }^{24}$ which is one of the most widely used questionnaires to evaluate heart failure specific QOL. ${ }^{11}$ The MLHFQ assesses the perception of the effect of heart failure and its treatment on the life of the patients. It is made up of 21 items that cover heart failure related physical, psychological, and social impairments. The patient's perception of such impairment is assessed on a scale ranging from no (score of 0 ) to very much (5). The total MLHFQ score is obtained by adding the scores for all 21 items (range, 0-105), and a higher score indicates a worse QOL. In addition, it is possible to calculate a summary score of the impact of heart failure on physical dimensions constructed on the basis of 8 items (range, 0
40 ), and another summary score of its impact on emotional dimensions constructed on the basis of 5 items (range, 0-25). Psychometric properties of the original and Japanese version of the MLHFQ have been confirmed. ${ }^{24,25}$

\section{Clinical Characteristics}

The following clinical information was collected from medical records at baseline: etiology of heart failure; duration of heart failure; prior hospitalizations for heart failure; New York Heart Association (NYHA) functional class; B-type natriuretic peptide (BNP); left ventricular ejection fraction (LVEF); left ventricular end-diastolic diameter; left arterial diameter by ultrasound cardiography; systolic/diastolic blood pressure; heart rate; atrial fibrillation including paroxysmal atrial fibrillation; hemoglobin concentration; estimated glomerular filtration rate (GFR) [calculated using the formula for Japanese, ${ }^{26}$ that is, estimated GFR $=194 \times \mathrm{age}^{-0.287} \times$ creatinine $^{-1.094}$ (and, if female, $\times 0.739)$ ]; comorbidity such as diabetes mellitus; and medication including $\beta$-blockers, angiotensin-converting enzyme (ACE) inhibitors and/or angiotensin II receptor blockers (ARBs), and warfarin.

\section{Demographic and Psychosocial Characteristics}

Patients were asked to complete a self-administered questionnaire to collect demographic and psychosocial variables including gender, age, marital status, educational level, employment, living situation, and depressive symptoms. Depressive symptoms were measured using the Japanese version of the Center for Epidemiologic Studies Depression Scale (CES-D). ${ }^{27,28}$ The CES-D is a 20-item self-report questionnaire designed for screening of depressive symptoms on a 4-point Likert scale ranging from 0 to 3 . A higher score indicates a greater tendency toward depressive symptoms. A total score of $\geq 16$ indicates the presence of depressive symptoms, and we classified patients with scores $\geq 16$ as suffering from depressive symptoms. Validity and reliability of the CES-D Japanese version have been confirmed by Shima et al. ${ }^{28}$

\section{Statistical Analysis}

Categorical data are presented as frequencies and percentages. For continuous variables with a normal distribution, the mean and standard deviations are reported. For variables not normally distributed, the median and inter-quartile ranges (IQR) are reported. In order to identify variables that related to QOL, univariate analysis was initially performed. The dependent variable was the total MLHFQ score, and independent variables were demographic, psychosocial, and clinical variables. Pearson's product-moment correlation coefficient or Spearman's rank-correlation coefficient was calculated for continuous variables, and the Student's t-test or MannWhitney U-test was used to evaluate differences between the 2 groups. After assessing the multicollinearity, multiple regression analysis was conducted, which included the variables related to the total MLHFQ score at $\mathrm{P}<0.10$ in univariate analysis.

The difference in survival between patients grouped by median of the total MLHFQ score was evaluated with a logrank test using Kaplan-Meier curves. A Cox proportional hazards model was constructed to assess the relationship between the MLHFQ score and subsequent endpoints after adjustment for the prognostic factors. The selection methods for the potential prognostic factors are described below. After we assessed multicollinearity, variables that were related to each endpoint at $\mathrm{P}<0.10$ in univariate Cox regression analysis were entered into the model. They were then selected 


\begin{tabular}{|c|c|}
\hline & n (\%) \\
\hline Gender, male & $84(73.7)$ \\
\hline Age, years & $64.7 \pm 15.8$ \\
\hline \multicolumn{2}{|l|}{ Marital status } \\
\hline Married & $81(71.1)$ \\
\hline Unmarried, divorced, widowed & $33(28.9)$ \\
\hline \multicolumn{2}{|l|}{ Education } \\
\hline$>12$ years & $51(44.7)$ \\
\hline$\leq 12$ years & $63(55.3)$ \\
\hline \multicolumn{2}{|l|}{ Employment } \\
\hline Employed & $52(45.6)$ \\
\hline Unemployed & $62(54.4)$ \\
\hline Living alone & $15(13.2)$ \\
\hline Depressive symptoms & $27(23.7)$ \\
\hline Ischemic etiology of HF & $33(28.9)$ \\
\hline Duration of $\mathrm{HF}$, years & $2.8(1.0-5.6)$ \\
\hline Prior hospitalization for $\mathrm{HF}$ & $50(43.9)$ \\
\hline NYHA functional class, I or II & $95(83.3)$ \\
\hline $\mathrm{BNP}, \mathrm{pg} / \mathrm{ml}$ & $121.6 \pm 163.9$ \\
\hline LVEF, \% & $53.1 \pm 13.3$ \\
\hline LVEF $\geq 50$ & $69(60.5)$ \\
\hline LVDd, mm (n=112) & $53.5 \pm 8.2$ \\
\hline LAD, $m m(n=111)$ & $45.0 \pm 11.5$ \\
\hline $\mathrm{LAD} \geq 42$ & $63(56.8)$ \\
\hline Systolic BP, mmHg & $125.3 \pm 20.8$ \\
\hline Diastolic BP, mmHg & $71.2 \pm 11.4$ \\
\hline Heart rate, beats/min & $71.1 \pm 12.3$ \\
\hline Atrial fibrillation & $41(36.0)$ \\
\hline Hemoglobin, g/dl & $13.2 \pm 2.2$ \\
\hline Estimated GFR, $\mathrm{ml} \cdot \mathrm{min}^{-1} \cdot 1.73 \mathrm{~m}^{-2}$ & $61.4 \pm 20.8$ \\
\hline Estimated GFR $<60$ & $57(50.0)$ \\
\hline Diabetes mellitus & $39(34.2)$ \\
\hline \multicolumn{2}{|l|}{ Medication } \\
\hline$\beta$-blockers & $60(52.6)$ \\
\hline ACE inhibitors and/or ARBs & $75(65.8)$ \\
\hline Digoxins & $36(31.6)$ \\
\hline Diuretics & $76(66.7)$ \\
\hline Warfarin & $53(46.5)$ \\
\hline \multicolumn{2}{|l|}{ The MLHFQ score } \\
\hline Total score & $31.6 \pm 23.0$ \\
\hline Physical summary score & $14.1 \pm 10.5$ \\
\hline Emotional summary score & $7.6 \pm 6.2$ \\
\hline
\end{tabular}

HF, heart failure; NYHA, New York Heart Association; BNP, B-type natriuretic peptide; LVEF, left ventricular ejection fraction; LVDd, left ventricular end-diastolic diameter; LAD, left atrial diameter; $\mathrm{BP}$, blood pressure; GFR, glomerular filtration rate; $\mathrm{ACE}$, angiotensin-converting-enzyme; ARB, angiotensin II receptor blocker; MLHFQ, the Minnesota Living with Heart Failure Questionnaire. Values are $n(\%)$, mean \pm standard deviation, or median (interquartile range).

using the backward method (the significance level required for retention in the model was 0.10 ).

All statistical tests were 2-tailed, and statistical significance was defined as $\mathrm{P}<0.05$. All analyses were performed with the SAS version 9.1 for Windows (SAS Institute Inc, Cary, NC, USA).

\begin{tabular}{|c|c|c|}
\hline & $\begin{array}{l}\text { Total MLHFQ } \\
\text { score }\end{array}$ & $P$ value \\
\hline \multicolumn{3}{|l|}{ Gender } \\
\hline Female & $42.4 \pm 25.2$ & 0.002 \\
\hline Male & $27.7 \pm 20.9$ & \\
\hline Age, years & 0.081 & 0.390 \\
\hline \multicolumn{3}{|l|}{ Marital status } \\
\hline Married & $32.9 \pm 22.8$ & 0.344 \\
\hline Unmarried & $28.4 \pm 23.3$ & \\
\hline \multicolumn{3}{|l|}{ Education } \\
\hline$>12$ years & $30.5 \pm 21.3$ & 0.645 \\
\hline$\leq 12$ years & $32.5 \pm 24.3$ & \\
\hline \multicolumn{3}{|l|}{ Employment } \\
\hline Employed & $28.2 \pm 20.9$ & 0.153 \\
\hline Unemployed & $34.4 \pm 24.3$ & \\
\hline \multicolumn{3}{|l|}{ Living alone } \\
\hline Yes & $28.9 \pm 25.6$ & 0.632 \\
\hline No & $32.0 \pm 22.6$ & \\
\hline \multicolumn{3}{|l|}{ Depressive symptoms } \\
\hline Yes & $52.5 \pm 23.1$ & $<0.001$ \\
\hline No & $25.1 \pm 18.7$ & \\
\hline \multicolumn{3}{|l|}{ Ischemic etiology of HF } \\
\hline Yes & $34.9 \pm 23.1$ & 0.323 \\
\hline No & $30.2 \pm 22.9$ & \\
\hline Duration of HF, years & -0.056 & 0.551 \\
\hline \multicolumn{3}{|l|}{ Prior hospitalization for HF } \\
\hline Yes & $35.0 \pm 22.3$ & 0.168 \\
\hline No & $29.0 \pm 23.3$ & \\
\hline \multicolumn{3}{|l|}{ NYHA functional class } \\
\hline I or II & $29.0 \pm 22.6$ & 0.006 \\
\hline III & $44.8 \pm 20.8$ & \\
\hline Log BNP, pg/ml & 0.251 & 0.007 \\
\hline LVEF, \% & -0.049 & 0.602 \\
\hline$\geq 50$ & $30.9 \pm 23.6$ & 0.672 \\
\hline$<50$ & $32.7 \pm 22.2$ & \\
\hline LVDd, mm (n=112) & -0.036 & 0.707 \\
\hline \multicolumn{3}{|l|}{ LAD, mm (n=111) } \\
\hline$\geq 42$ & $35.0 \pm 24.1$ & 0.041 \\
\hline$<42$ & $26.3 \pm 18.9$ & \\
\hline Systolic BP, par $10 \mathrm{mmHg}$ & -0.037 & 0.698 \\
\hline Diastolic BP, par $10 \mathrm{mmHg}$ & -0.036 & 0.701 \\
\hline Heart rate, beats/min & 0.090 & 0.343 \\
\hline \multicolumn{3}{|l|}{ Atrial fibrillation } \\
\hline Yes & $36.0 \pm 25.4$ & 0.125 \\
\hline No & $29.1 \pm 21.3$ & \\
\hline Hemoglobin, g/dl & -0.270 & 0.004 \\
\hline \multicolumn{3}{|c|}{ Estimated GFR, $\mathrm{ml} \cdot \mathrm{min}^{-1} \cdot 1.73 \mathrm{~m}^{-2}$} \\
\hline$\geq 60$ & $24.9 \pm 22.9$ & 0.002 \\
\hline$<60$ & $38.3 \pm 21.2$ & \\
\hline \multicolumn{3}{|l|}{ Diabetes mellitus } \\
\hline Yes & $32.8 \pm 23.1$ & 0.677 \\
\hline No & $30.9 \pm 23.0$ & \\
\hline
\end{tabular}

(Table 2 continued next page.) 


\begin{tabular}{|lcc|}
$\begin{array}{l}\text { Medication } \\
\beta \text {-blockers }\end{array}$ & $\begin{array}{c}\text { Total MLHFQ } \\
\text { score }\end{array}$ & P value \\
Yes & & \\
No & $28.8 \pm 17.8$ & 0.171 \\
ACE inhibitors and/or ARBs & $34.7 \pm 27.4$ & \\
$\quad$ Yes & $31.5 \pm 23.9$ & 0.968 \\
$\quad$ No & $31.7 \pm 21.4$ & \\
Digoxins & & \\
$\quad$ Yes & $38.3 \pm 29.5$ & 0.033 \\
$\quad$ No & $28.5 \pm 18.6$ & \\
Diuretics & & \\
Yes & $35.6 \pm 22.5$ & 0.008 \\
No & $23.6 \pm 22.0$ & \\
Warfarin & & \\
Yes & $34.8 \pm 24.8$ & 0.162 \\
No & $28.8 \pm 21.0$ & \\
\hline
\end{tabular}

Quality of Life was assessed with the Minnesota Living with Heart Failure Questionnaire; higher scores represent more impaired quality of life. Values are mean \pm SD, Pearson's product-moment correlation coefficient, or Spearman's rank-correlation coefficient. Abbreviations as per Table 1.

\section{Results}

\section{Baseline Characteristics of Study Patients}

A total of 124 patients participated in the survey. Ten patients were excluded for the following reasons: 2 patients did not return the questionnaire, more than $80 \%$ of all items were missing in the questionnaire of 7 patients, and the medical data of 1 patient was not available at baseline. Thus, 114

\begin{tabular}{|lcc|}
\hline Table 3. Independent Determinants of Quality of Life Among \\
HF Patients in Multiple Regression Analysis $(\mathbf{n}=111)$
\end{tabular}

Quality of Life was assessed with the Minnesota Living with Heart Failure Questionnaire; higher scores represent more impaired quality of life.

$\mathrm{s} \beta$, standard partial regression coefficients. Other abbreviations as per Table 1.

After we assessed the multicollinearity, variables that were related to the quality of life score at $\mathrm{P}<0.10$ in univariate analysis (Table 2) were entered into the multivariate model. Because there was a significant relationship between log BNP level and NYHA functional class, we used the variables of log BNP instead of NYHA functional class in multiple regression analyses.

patients were included in the final analysis. The effective response rate was $91.9 \%$. Characteristics of patients were not different between patients who were included in the study and those who were not.

Characteristics of study patients are shown in Table 1 . The patients were 64.7 years old, and $73.7 \%$ were male. Heart failure of ischemic etiology was present in $28.9 \%$ of the patients. The mean BNP was $121.6 \pm 163.9 \mathrm{pg} / \mathrm{ml}$. The mean LVEF

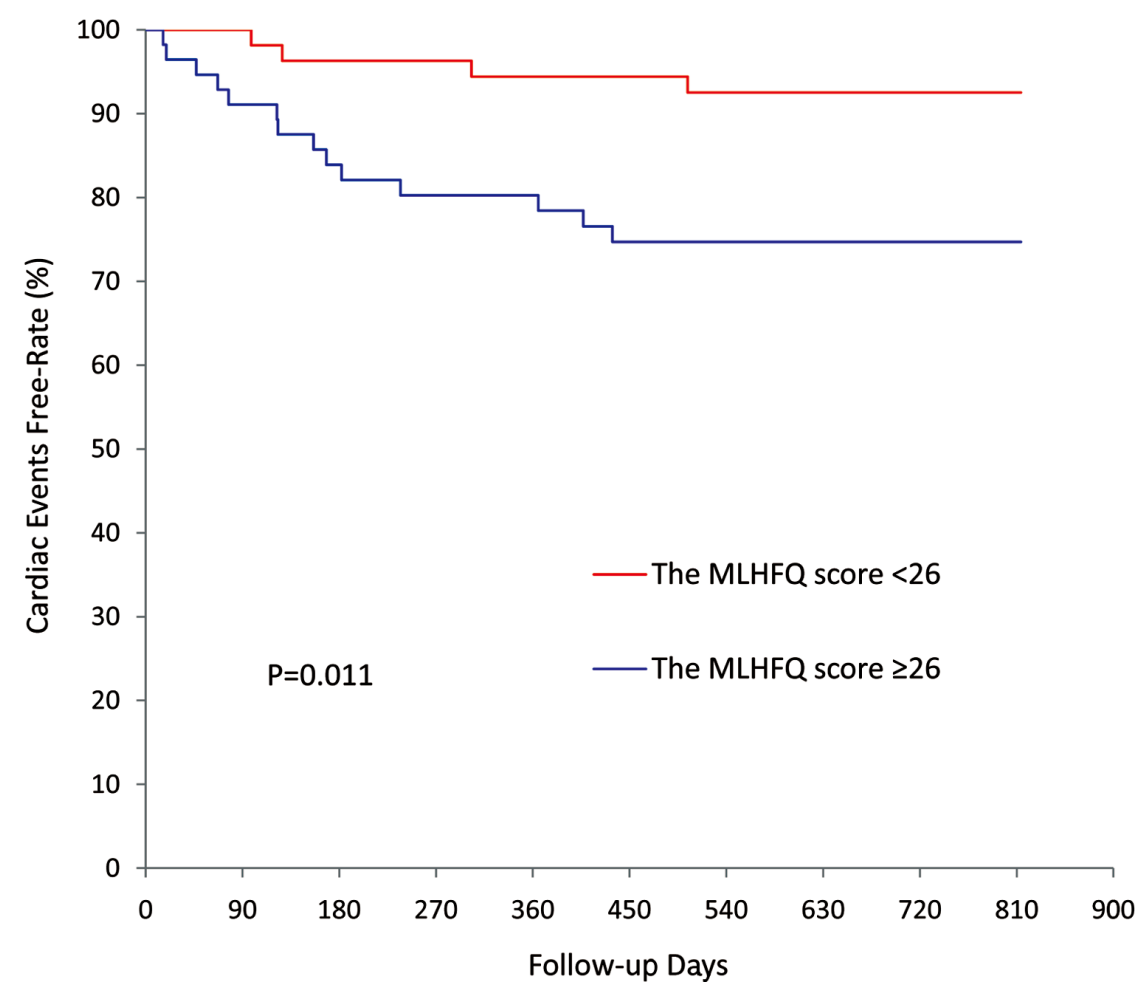

Figure 1. Kaplan-Meier curves for cardiac event-free survival according to the Minnesota Living with Heart Failure Questionnaire (MLHFQ) score. Cardiac events represent cardiac death or hospitalization for heart failure. 


\begin{tabular}{|c|c|c|c|c|}
\hline & \multicolumn{2}{|c|}{$\begin{array}{l}\text { Cardiac death or } \\
\text { hospitalizatio for HF }\end{array}$} & \multicolumn{2}{|c|}{ All-cause death } \\
\hline & HR (95\%Cl) & $P$ value & $\mathrm{HR}(95 \% \mathrm{Cl})$ & $P$ value \\
\hline \multicolumn{5}{|l|}{ The MLHFQ score } \\
\hline Total score & $1.03(1.02-1.05)$ & $<0.001$ & $1.04(1.02-1.06)$ & $<0.001$ \\
\hline Physical summary score & $1.08(1.03-1.12)$ & $<0.001$ & $1.10(1.04-1.16)$ & $<0.001$ \\
\hline Emotional summary score & $1.12(1.05-1.20)$ & 0.001 & $1.15(1.05-1.25)$ & 0.002 \\
\hline Gender, female vs. male* & $2.68(1.06-6.79)$ & 0.038 & $3.57(1.15-11.09)$ & 0.028 \\
\hline Age, years & $1.03(0.99-1.06)$ & 0.170 & $1.02(0.98-1.07)$ & 0.324 \\
\hline \multicolumn{5}{|l|}{ Marital status } \\
\hline Married vs. others* & $1.10(0.39-3.10)$ & 0.850 & $0.86(0.26-2.86)$ & 0.808 \\
\hline Education $>12$ vs. $\leq 12^{*}$, years & $0.61(0.23-1.63)$ & 0.325 & $0.41(0.11-1.50)$ & 0.177 \\
\hline \multicolumn{5}{|l|}{ Employment } \\
\hline Employed vs. unemployed* & $0.58(0.22-1.54)$ & 0.271 & $0.37(0.10-1.38)$ & 0.139 \\
\hline Depressive symptoms & $4.14(1.64-10.44)$ & 0.003 & $5.79(1.84-18.28)$ & 0.003 \\
\hline Ischemic etiology of HF & $0.96(0.34-2.70)$ & 0.940 & $0.80(0.22-2.96)$ & 0.740 \\
\hline Duration of $\mathrm{HF}$, years & $1.001(0.91-1.10)$ & 0.982 & $1.07(0.97-1.17)$ & 0.192 \\
\hline Prior hospitalization for $\mathrm{HF}$ & $3.32(1.19-9.33)$ & 0.023 & $1.68(0.53-5.28)$ & 0.379 \\
\hline \multicolumn{5}{|l|}{ NYHA functional class } \\
\hline III vs. I or II* & $14.58(5.42-39.21)$ & $<0.001$ & 8.49 (2.69-26.88) & $<0.001$ \\
\hline Log BNP & $2.92(1.85-4.61)$ & $<0.001$ & $2.07(1.20-3.57)$ & 0.009 \\
\hline LVEF, \% & $0.96(0.93-0.998)$ & 0.038 & $0.98(0.94-1.02)$ & 0.259 \\
\hline LVEF $\geq 50$ vs. $<50^{*}, \%$ & $0.41(0.16-1.06)$ & 0.064 & $0.64(0.21-1.98)$ & 0.437 \\
\hline LVDd, mm & $0.998(0.94-1.06)$ & 0.946 & $0.94(0.88-1.01)$ & 0.077 \\
\hline LAD, $\geq 42$ vs. $<42^{*}, \mathrm{~mm}$ & $1.85(0.65-5.24)$ & 0.250 & $2.13(0.57-8.04)$ & 0.264 \\
\hline Systolic BP, par $10 \mathrm{mmHg}$ & $0.75(0.58-0.96)$ & 0.024 & $0.84(0.64-1.12)$ & 0.237 \\
\hline Diastolic BP, par $10 \mathrm{mmHg}$ & $0.58(0.39-0.86)$ & 0.006 & $0.70(0.44-1.11)$ & 0.127 \\
\hline Heart rate, beats/min & $1.01(0.98-1.05)$ & 0.496 & $1.01(0.97-1.06)$ & 0.572 \\
\hline Atrial fibrillation & $1.97(0.78-4.96)$ & 0.151 & $1.38(0.44-4.36)$ & 0.579 \\
\hline Hemoglobin, g/dl & $0.64(0.50-0.82)$ & 0.001 & $0.71(0.53-0.95)$ & 0.022 \\
\hline \multicolumn{5}{|l|}{ Estimated GFR } \\
\hline$<60$ vs. $\geq 60^{\star}, \mathrm{ml} \cdot \mathrm{min}^{-1} \cdot 1.73 \mathrm{~m}^{-2}$ & $5.39(1.56-18.62)$ & 0.008 & $3.02(0.82-11.14)$ & 0.098 \\
\hline \multicolumn{5}{|l|}{ Medication } \\
\hline$\beta$-blockers & $0.15(0.04-0.52)$ & 0.003 & & \\
\hline ACE inhibitors and/or ARBs & $0.30(0.12-0.78)$ & 0.014 & $0.15(0.04-0.55)$ & 0.004 \\
\hline Digoxins & $3.87(1.50-9.98)$ & 0.005 & $2.46(0.79-7.68)$ & 0.121 \\
\hline Diuretics & $4.32(0.99-18.77)$ & 0.051 & $2.59(0.57-11.83)$ & 0.219 \\
\hline Warfarin & $1.97(0.76-5.09)$ & 0.160 & $1.97(0.76-5.09)$ & 0.160 \\
\hline
\end{tabular}

For the MLHFQ, higher scores represent more impaired quality of life. *Reference category.

$\mathrm{HR}$, hazard ratio; $\mathrm{Cl}$, confidence interval. Other abbreviations as per Table 1.

was $53.1 \%$ and a left atrial diameter of more than $42 \mathrm{~mm}$ was present in $56.8 \%$ of the patients. Forty-one patients $(36.0 \%)$ had atrial fibrillation, including 7 patients $(6.1 \%)$ with paroxysmal atrial fibrillation. Twenty-seven patients (23.7\%) were classified as patients with depressive symptoms. And half of patients had chronic kidney disease defined as an estimated GFR of less than 60. Regarding medication, ACE inhibitors and/or ARBs, and $\beta$-blockers were prescribed to $65.8 \%$ and $52.6 \%$ of patients, respectively. Fifty-three patients $(46.5 \%)$ were treated with warfarin. The total MLHFQ score was $31.6 \pm 23.0$.

\section{Factors Associated With QOL}

Table 2 compares the total MLHFQ score between the 2 populations stratified by various patients' characteristics. Female and patients with depressive symptoms had the higher total score of the MLHFQ, indicating a worse QOL $(\mathrm{P}=0.002$ and
$\mathrm{P}<0.001$, respectively). As to heart failure severity, the $\log$ BNP level and NYHA functional class but not LVEF was positively associated with a worse QOL $(\mathrm{r}=0.251, \mathrm{P}=0.007$; and $\mathrm{P}=0.006$; respectively). Additionally, a lower level of hemoglobin and the presence of an estimated GFR $<60$ were significantly associated with impaired QOL $(\mathrm{P}=0.004$ and $\mathrm{P}=0.002$, respectively).

Because there was a significant relationship between log BNP level and NYHA functional class $(\rho=0.404, \mathrm{P}<0.001)$, we used the variables of $\log$ BNP instead of NYHA functional class in multivariate analyses. Multiple regression analysis revealed that depressive symptoms [standard partial regression coefficients $(\mathrm{s} \beta)=0.44, \mathrm{P}<0.001$ ] and the estimated GFR of less than $60(\mathrm{~s} \beta=0.18, \mathrm{P}=0.038)$ were significant predictors of a worse QOL (Table 3). 


\begin{tabular}{|c|c|c|}
\hline & HR (95\% Cl) & $P$ value \\
\hline \multicolumn{3}{|l|}{ Cardiac death or hospitalization for HF } \\
\hline Total MLHFQ score & $1.02(1.001-1.05)$ & 0.038 \\
\hline LVEF, \% & $0.93(0.89-0.97)$ & 0.002 \\
\hline$\beta$-blockers & $0.12(0.03-0.48)$ & 0.002 \\
\hline Estimated GFR, $<60 \mathrm{ml} \cdot \mathrm{min}^{-1} \cdot 1.73 \mathrm{~m}^{-2}$ & $5.28(1.36-20.47)$ & 0.016 \\
\hline Systolic BP, par $10 \mathrm{mmHg}$ & $0.79(0.64-0.98)$ & 0.035 \\
\hline ACE inhibitors and/or ARBs & $0.32(0.11-0.95)$ & 0.039 \\
\hline Hemoglobin, g/dl & $0.80(0.64-1.003)$ & 0.053 \\
\hline \multicolumn{3}{|l|}{ All-cause death } \\
\hline Total MLHFQ score & $1.04(1.02-1.07)$ & 0.001 \\
\hline Log BNP & $0.11(0.03-0.44)$ & 0.002 \\
\hline ACE inhibitors and/or ARBs & $1.76(0.94-3.30)$ & 0.078 \\
\hline
\end{tabular}

Quality of Life was assessed with the Minnesota Living with Heart Failure Questionnaire; higher scores represent more impaired quality of life.

Abbreviations as per Tables 1,4.

After we assessed the multicollinearity, variables that were related to each endpoint at $P<0.10$ in univariate Cox regression analysis (Table 4) were entered into the multivariate model. They were then selected using the backward method (the significance level required for retention in the model was 0.10 ). Because there were significant relationships between log BNP level and NYHA functional class, and between systolic and diastolic BP levels, we used the variables of $\log$ BNP instead of NYHA functional class and of systolic BP instead of diastolic BP in multivariate analyses.

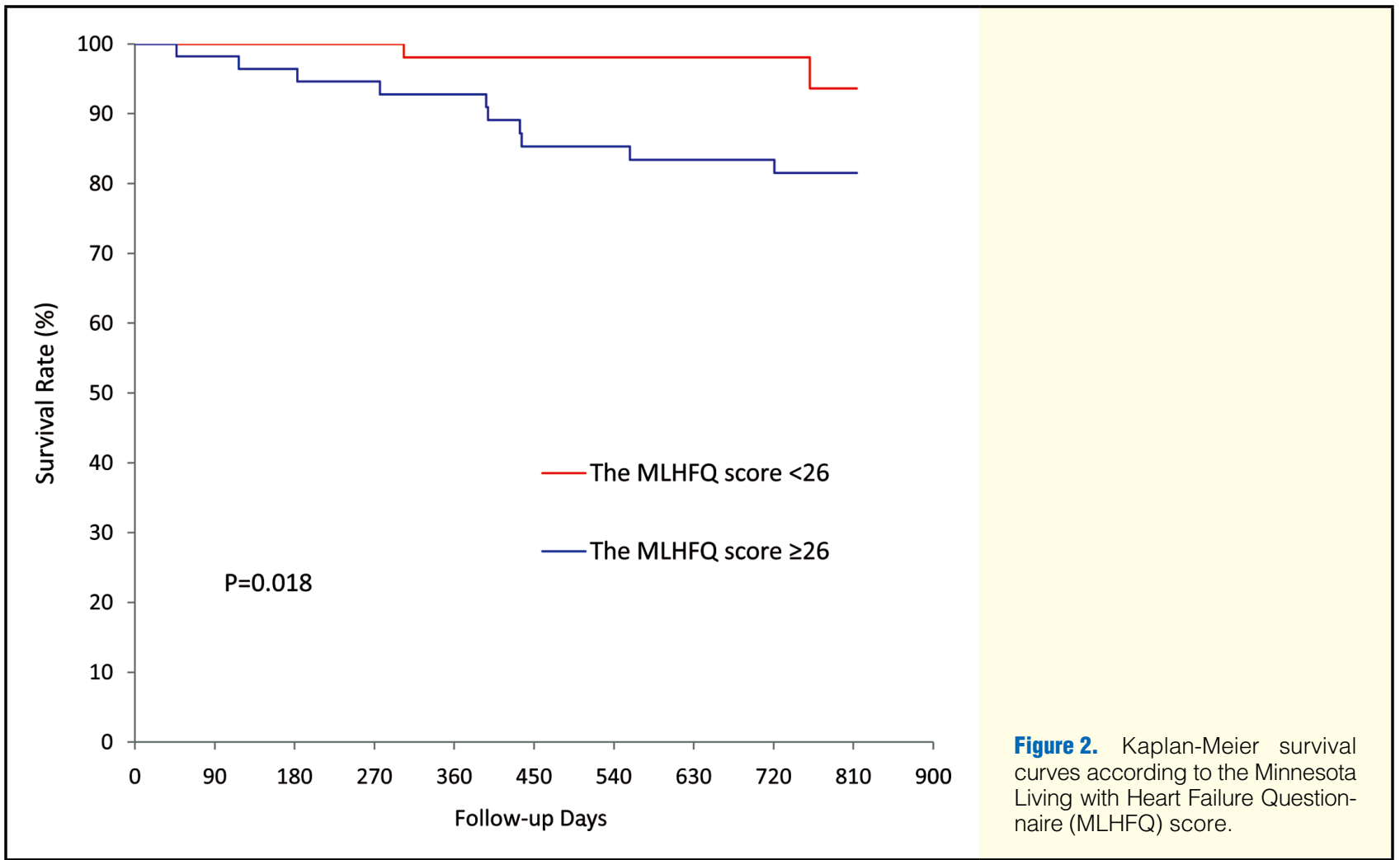

\section{Association of QOL With Clinical Outcomes}

The median follow-up period was 756 days (IQR, 738-781). Of the 114 patients, the vital status data were available in 110 patients (96.5\%). During follow up, 18 patients had the combined endpoint of cardiac death or hospitalization for heart failure. Fifteen patients were hospitalized for decompensated heart failure, and 12 patients died, 8 of them from a cardiac cause. For all patients, the cumulative 1- and 2-year combined endpoint rates and mortality were $13.7 \%$ and $16.5 \%$, and $4.6 \%$ and $10.3 \%$, respectively.

In heart failure patients with a total MLHFQ score of $\geq 26$, an indicating worse QOL score, the rate of cardiac death or heart failure hospitalization was greater compared with those with a score of $<26[25.3 \%$ vs. $7.5 \%, \mathrm{P}=0.011$, Figure 1; hazard ratio (HR) 1.95; 95\% confidence interval (CI), 1.123.40; $\mathrm{P}=0.018]$. Table 4 shows the results of univariate $\mathrm{Cox}$ regression analysis. The total MLHFQ score was related to an increased risk for cardiac death or hospitalization for heart 
failure (HR, 1.03 for each 1 unit increase; 95\%CI, 1.02-1.05; $\mathrm{P}<0.001)$. Similar trends were observed in the physical summary score $(\mathrm{HR}, 1.08 ; 95 \% \mathrm{CI}, 1.03-1.12 ; \mathrm{P}<0.001)$ and the emotional summary score (HR, 1.12; 95\%CI, 1.05-1.20; $\mathrm{P}=$ 0.001). Factors associated with increased cardiac death or hospitalization for heart failure in univariate analysis were as follows: female, depressive symptoms, prior hospitalization for heart failure, higher NYHA functional class, higher BNP level, lower LVEF, lower systolic blood pressure, lower diastolic blood pressure, lower hemoglobin level, estimated GFR $<60$, non-use of $\beta$-blockers, non-use of ACE inhibitors and/or ARBs, and use of digoxins.

In addition to the significant relationship between log BNP level and NYHA functional class described above, there was a strong association between systolic and diastolic blood pressure levels $(\rho=0.704, \mathrm{P}<0.001)$. Thus, we used the variables of systolic blood pressure instead of diastolic blood pressure, as well as the variable of log BNP instead of NYHA functional class in multivariate analyses. Multivariate Cox regression analyses revealed that the MLHFQ score was significantly associated with an increased risk for the combined endpoint of cardiac death and hospitalization for heart failure, independent of other prognostic factors including LVEF, use of $\beta$-blockers, and the presence of estimated GFR $<60$ (HR, 1.02; 95\%CI, 1.001-1.05; $\mathrm{P}=0.038$; Table 5).

With respect to all-cause death, patients with a total MLHFQ score of $\geq 26$ had a higher mortality than those with a score of $<26(18.5 \%$ vs. $6.4 \% ; \mathrm{P}=0.018$; Figure 2 ; HR, 2.27; 95\%CI, 1.06-4.86; $\mathrm{P}=0.034)$. The total MLHFQ score was associated with an increased mortality (HR, 1.04; 95\%CI, 1.02-1.06; $\mathrm{P}<0.001$; Table 4). The physical summary score (HR, 1.10; 95\%CI, 1.04-1.16; $\mathrm{P}<0.001$ ) and emotional summary score (HR, 1.15; 95\% CI, 1.05-1.25; $\mathrm{P}=0.002)$ were also related to mortality. Univariate analyses showed that female, depressive symptoms, higher NYHA functional class, higher BNP level, lower hemoglobin level, and non-use of ACE inhibitors and/or ARBs were significantly associated with increased mortality (Table 4). Because none of the deceased patients were prescribed $\beta$-blockers, we could not calculate the hazard ratio concerning use of $\beta$-blockers. In multivariate analyses, the total MLHFQ score was again a significant predictive factor for all-cause death, which was independent of the use of ACE inhibitors and/or ARBs and BNP level (HR, 1.04; 95\%CI, 1.02-1.07; P=0.001; Table 5).

\section{Discussion}

This study was a 2-year prospective follow-up study among Japanese outpatients with mild to moderate heart failure. We showed that depressive symptoms and chronic kidney disease were risk factors for worse QOL independently of disease severity in patients with heart failure. We also demonstrated that the QOL score could predict both the combined endpoint of cardiac death or hospitalization for heart failure, and all-cause death, independently of other prognostic factors in Japanese patients with heart failure. This suggests that knowledge of health status, as measured by the MLHFQ, might both provide a unique window into their clinical status and be prognostically important, such that it can enhance secondary prevention intervention by means of identifying high-risk patients at a relatively low cost.

\section{Determinants of QOL}

Depressive symptoms were strongly associated with impaired QOL, independently of disease severity assessed by BNP level, which expands the results of earlier studies.,9 Prior studies have also shown that impaired QOL was predictive of the development of depression. ${ }^{29}$ Comorbid depressive symptoms, which is common in patients with heart failure, has an additional impact on patients' increased morbidity and mortality ${ }^{19,30}$ as well as negatively influencing a patient's adherence to therapy. ${ }^{31}$ Given the severe restrictions in QOL because of depressive symptoms and the resulting pronouncedly negative effect on the course and prognosis of patient's cardiac disease, our finding suggests that an accurate diagnosis of depressive comorbidity in patients with heart failure is essential when it comes to initiating adequate treatment.

An interesting finding was that chronic kidney disease, defined as an estimated GFR of less than 60 was an independent risk factor for worse QOL in heart failure patients. Although chronic kidney disease has been established as a predictor for morbidity and mortality, ${ }^{32,33}$ it has not well-known as an independent risk factor for impaired QOL in patients with heart failure. A study of 1186 chronic kidney disease patients has found that a history of cardiovascular co-morbidity was associated with impaired QOL. ${ }^{34}$ These observations highlight the profound impact of chronic kidney disease on heart failure, and suggest potential areas that can be targeted for therapeutic intervention.

Regarding LVEF, our result was consistent with that from the CHARM study. ${ }^{35}$ The re-hospitalization rate as well as QOL in heart failure patients with preserved EF has shown to be similar compared with those with reduced EF.,235 Improvement in QOL and preventing re-hospitalization are important objectives in all patients with heart failure, irrespectively of LVEF.

\section{Relationship of QOL With Clinical Outcomes}

It is noteworthy that the MLHFQ score predicted all-cause death as well as the combined endpoint of cardiac death or hospitalization for heart failure, independently of the established prognostic factors and medication. In previous studies, there has been a discrepancy in the association between the QOL score and subsequent mortality, and it has not been consistent whether the QOL score predicts clinical outcomes after fully adjusting for prognostic factors. ${ }^{12}$ Our results support that the QOL score could provide prognostic information in addition to conventional factors such as LVEF and estimated GFR. ${ }^{12-15,18}$ Moreover, recent sub-analyses from EPHESUS has shown that the QOL score predicted resource use and the cost over the next year for stable heart failure patients after myocardial infarction. ${ }^{36}$ Taking these observations into consideration, self-reported health status, including QOL, is useful for identifying high-risk heart failure patients who might be candidates for more intensive therapy including cardiology referral and a heart failure management program.

With respect to the mechanism between QOL and subsequent clinical outcomes, the worse QOL score has been shown to be related to inflammatory burden including interleukin-6, implying a close relationship between self-reported health status and the biochemical pathogenetic mechanisms of heart failure progression. ${ }^{37}$ Immune activation has been shown to be associated with increased emotional distress and depressive symptoms. ${ }^{38}$ This pathophysiological aspect might possibly explain the relationship of impaired QOL with depressive symptoms and clinical outcomes.

\section{Study Limitations}

Our study has several potential limitations. First, the gener- 
alizability of this study was limited as all patients were recruited from a cardiovascular outpatient clinic at a single university hospital in Tokyo. Second, a cross-sectional assessment of variables including depressive symptoms, chronic kidney disease and the MLHFQ score cannot confirm a causative relationship. Third, small sample size and low frequency of clinical events in this study limited the number of variables examined in multivariate analyses and the statistical significance of our findings; additional variables might have significant contributions in a larger study. Fourth, we did not assess adherence to treatment. Adherence to pharmacological and non-pharmacological treatment is likely to have an influence on patient's QOL and clinical outcomes. Finally, QOL was assessed at only baseline in this study; using only 1 snapshot assessment might miss the true nature of QOL in a given individual. The relationship of a change of QOL and subsequent clinical outcomes needs to be investigated in future research.

\section{Conclusions}

This study has found that depressive symptoms and chronic kidney disease are risk factors for impaired QOL, independently of disease severity among patients with heart failure. We have also demonstrated that the MLHFQ score is associated with increased risk of all-cause death as well as the combined endpoint of cardiac death or hospitalization for heart failure. The MLHFQ score is an independent risk factor for the prognosis of heart failure patients. Future effort to improve the QOL of patients with heart failure should include a focus on depressive symptoms and chronic kidney disease. Measurement of QOL is an attractive and inexpensive method of estimating a heart failure patient's prognosis for healthcare professionals interested in identifying high-risk patients for specific intervention.

\section{Acknowledgments}

We wish to express our sincere gratitude to Dr Norihiko Takeda, MD, $\mathrm{PhD}$; Dr Yasushi Imai, MD, PhD; and Dr Masafumi Watanabe, MD, $\mathrm{PhD}$ from the Department of Cardiovascular Medicine, University of Tokyo Hospital for helping with the recruitment of study participants and data collection. This study was supported, in part, by a Grant-in-Aid for the JSPS Postdoctoral Research Fellow from the Japan Society for the Promotion of Science (no.224943) to N.K.. The data in this paper was presented, in part, at the $73^{\text {rd }}$ Annual Scientific Meeting of the Japanese Circulation Society (Osaka, Japan, 2009).

\section{References}

1. Jessup M, Brozena S. Heart failure. N Engl J Med 2003; 348: 2007-2018.

2. Tsuchihashi-Makaya M, Hamaguchi S, Kinugawa S, Yokota T, Goto $\mathrm{D}$, Yokoshiki H, et al. Characteristics and outcomes of hospitalized patients with heart failure and reduced vs preserved ejection fraction: Report from the Japanese Cardiac Registry of Heart Failure in Cardiology (JCARE-CARD). Circ J 2009; 73: 1893-1900.

3. Ohno Y, Okura Y, Ramadan MM, Taneda K, Suzuki K, Tomita M, et al. Health-related quality of life of outpatients with systolic and isolated diastolic dysfunction: Sado Heart Failure Study. Circ J 2008; 72: 1436-1442.

4. Mitani H, Hashimoto H, Isshiki T, Kurokawa S, Ogawa K, Matsumoto K, et al. Health-related quality of life of Japanese patients with chronic heart failure: Assessment using the Medical Outcome Study Short Form 36. Circ J 2003; 67: 215-220.

5. Hobbs FD, Kenkre JE, Roalfe AK, Davis RC, Hare R, Davies MK, et al. Impact of heart failure and left ventricular systolic dysfunction on quality of life: A cross-sectional study comparing common chronic cardiac and medical disorders and a representative adult population. Eur Heart J 2002; 23: 1867-1876.

6. Bekelman DB, Havranek EP, Becker DM, Kutner JS, Peterson PN, Wittstein IS, et al. Symptoms, depression, and quality of life in patients with heart failure. J Card Fail 2007; 13: 643-648.

7. Rector TS, Anand IS, Cohn JN. Relationships between clinical assessments and patients' perceptions of the effects of heart failure on their quality of life. J Card Fail 2006; 12: 87-92.

8. Ruo B, Rumsfeld JS, Hlatky MA, Liu H, Browner WS, Whooley MA. Depressive symptoms and health-related quality of life: The Heart and Soul Study. JAMA 2003; 290: 215-221.

9. Müller-Tasch T, Peters-Klimm F, Schellberg D, Holzapfel N, Barth A, Jünger J, et al. Depression is a major determinant of quality of life in patients with chronic systolic heart failure in general practice. J Card Fail 2007; 13: 818-824.

10. Faller H, Störk S, Schuler M, Schowalter M, Steinbüchel T, Ertl G, et al. Depression and disease severity as predictors of health-related quality of life in patients with chronic heart failure--a structural equation modeling approach. J Card Fail 2009; 15: 286-29, e282.

11. Garin O, Ferrer M, Pont A, Rue M, Kotzeva A, Wiklund I, et al. Disease-specific health-related quality of life questionnaires for heart failure: A systematic review with meta-analyses. Qual Life Res 2009; 18: 71-85.

12. Mommersteeg PMC, Denollet J, Spertus JA, Pedersen SS. Health status as a risk factor in cardiovascular disease: A systematic review of current evidence. Am Heart J 2009; 157: 208-218.

13. Carson P, Tam SW, Ghali JK, Archambault WT, Taylor A, Cohn JN, et al. Relationship of quality of life scores with baseline characteristics and outcomes in the African-American heart failure trial. $J$ Card Fail 2009; 15: 835-842.

14. Tate CW 3rd, Robertson AD, Zolty R, Shakar SF, Lindenfeld J, Wolfel EE, et al. Quality of life and prognosis in heart failure: Results of the Beta-Blocker Evaluation of Survival Trial (BEST). J Card Fail 2007; 13: 732-737.

15. Heidenreich PA, Spertus JA, Jones PG, Weintraub WS, Rumsfeld JS, Rathore SS, et al. Health status identifies heart failure outpatients at risk for hospitalization or death. J Am Coll Cardiol 2006; 47: $752-756$.

16. Rodriguez-Artalejo F, Guallar-Castillon P, Pascual CR, Otero CM, Montes AO, Garcia AN, et al. Health-related quality of life as a predictor of hospital readmission and death among patients with heart failure. Arch Intern Med 2005; 165: 1274-1279.

17. Alla F, Briancon S, Guillemin F, Juilliere Y, Mertes PM, Villemot $\mathrm{JP}$, et al. Self-rating of quality of life provides additional prognostic information in heart failure: Insights into the EPICAL study. Eur J Heart Fail 2002; 4: 337-343.

18. Konstam V, Salem D, Pouleur H, Kostis J, Gorkin L, Shumaker S, et al. Baseline quality of life as a predictor of mortality and hospitalization in 5,025 patients with congestive heart failure. SOLVD Investigations: Studies of Left Ventricular Dysfunction Investigators. Am J Cardiol 1996; 78: 890-895.

19. Kato N, Kinugawa K, Yao A, Hatano M, Shiga T, Kazuma K. Relationship of depressive symptoms with hospitalization and death in Japanese patients with heart failure. J Card Fail 2009; 15: $912-$ 919.

20. Kato N, Ito N, Kinugawa K, Kazuma K. Validity and reliability of the Japanese version of the European Heart Failure Self-Care Behavior Scale. Eur J Cardiovasc Nurs 2008; 7: 284-289.

21. Kato N, Kinugawa K, Ito N, Yao A, Watanabe M, Imai Y, et al. Adherence to self-care behavior and factors related to this behavior among patients with heart failure in Japan. Heart Lung 2009; 38: 398-409.

22. McKee PA, Castelli WP, McNamara PM, Kannel WB. The natural history of congestive heart failure: The Framingham study. N Engl J Med 1971; 285: 1441-1446.

23. Finkelstein FO, Wuerth D, Finkelstein SH. Health related quality of life and the CKD patient: Challenges for the nephrology community. Kidney Int 2009; 76: 946-952.

24. Rector TS, Francis GS, Cohn JN. Patients self-assessment of their congestive heart failure. Part 2: Content, reliability and validity of a new measure, the Minnesota living with heart failure questionnaire. Heart Fail 1987; 3: 198-209.

25. Origasa H, Owa M, Zhu Y, Morioka T. Reliabity of the new quality of life instrument for patients with heart failure. Jpn J Clin Pharmacol Ther 2002; 33: 263S-264S.

26. Matsuo S, Imai E, Horio M, Yasuda Y, Tomita K, Nitta K, et al. Revised equations for estimated GFR from serum creatinine in Japan. Am J Kidney Dis 2009; 53: 982-992.

27. Radloff LS. The CES-D scale: A self-report depression scale for research in the general population. Appl Psychol Meas 1977; 1: $385-$ 401.

28. Shima S, Shikano T, Kitamura T, Arai T. New self-rating scales for depression. Clin Psychiatry 1985; 27: 717-723.

29. Havranek EP, Spertus JA, Masoudi FA, Jones PG, Rumsfeld JS, 
Havranek EP, et al. Predictors of the onset of depressive symptoms in patients with heart failure. J Am Coll Cardiol 2004; 44: 2333 2338.

30. Rutledge T, Reis VA, Linke SE, Greenberg BH, Mills PJ. Depression in heart failure a meta-analytic review of prevalence, intervention effects, and associations with clinical outcomes. J Am Coll Cardiol 2006; 48: 1527-1537.

31. DiMatteo MR, Lepper HS, Croghan TW. Depression is a risk factor for noncompliance with medical treatment: Meta-analysis of the effects of anxiety and depression on patient adherence. Arch Intern Med 2000; 160: 2101-2107.

32. Komukai K, Ogawa T, Yagi H, Date T, Sakamoto H, Kanzaki Y, et al. Decreased renal function as an independent predictor of rehospitalization for congestive heart failure. Circ J 2008; 72: 1152 1157.

33. Hamaguchi S, Tsuchihashi-Makaya M, Kinugawa S, Yokota T, Ide $\mathrm{T}$, Takeshita A, et al. Chronic kidney disease as an independent risk for long-term adverse outcomes in patients hospitalized with heart failure in Japan: Report from the Japanese Cardiac Registry of Heart Failure in Cardiology (JCARE-CARD). Circ J 2009; 73:
$1442-1447$.

34. Mujais SK, Story K, Brouillette J, Takano T, Soroka S, Franek C, et al. Health-related quality of life in CKD Patients: Correlates and evolution over time. Clin J Am Soc Nephrol 2009; 4: 1293-1301.

35. Lewis EF, Lamas GA, O'Meara E, Granger CB, Dunlap ME, McKelvie RS, et al. Characterization of health-related quality of life in heart failure patients with preserved versus low ejection fraction in CHARM. Eur J Heart Fail 2007; 9: 83-91.

36. Chan PS, Soto G, Jones PG, Nallamothu BK, Zhang Z, Weintraub WS, et al. Patient health status and costs in heart failure: Insights from the eplerenone post-acute myocardial infarction heart failure efficacy and survival study (EPHESUS). Circulation 2009; 119: $398-407$.

37. Parissis JT, Nikolaou M, Farmakis D, Paraskevaidis IA, Bistola V, Venetsanou K, et al. Self-assessment of health status is associated with inflammatory activation and predicts long-term outcomes in chronic heart failure. Eur J Heart Fail 2009; 11: 163-169.

38. Howren MB, Lamkin DM, Suls J. Associations of depression with C-reactive protein, IL-1, and IL-6: A meta-analysis. Psychosom Med 2009; 71: $171-186$ 